\title{
Editorial
}

\section{Review of PCST2012 conference: where is communication going?}

The biennial international conference on public communication of science and technology (PCST) is an unusual event. It combines elements of an academic conference, where research results and theories are discussed, with those of a professional conference, where practitioners exchange experiences. The conference's mixed character presents particular challenges in organising it and in assessing it.

The raw numbers of the April 2012 conference in Firenze indicate that PCST is in a healthy state - nearly 700 registered participants and over 450 presentations of various kinds. Many more proposals were received but could not be accommodated. The participants were evenly divided between those who research, teach or study PCST and those who are professionally engaged in it or scientists who practise it. Two-thirds were attending their first PCST conference, indicating that there is strong growth in these fields of activity.

One hundred sessions were packed into two very crowded days, along with performances, screenings and poster displays. Respondents to a post-conference evaluation stated repeatedly that they found this too dense and thought the conference should be longer in order to reduce the clashes between simultaneous sessions. This might be taken as another indication of good health: people are willing to invest more time in presenting, hearing and discussing latest developments.

But what can we say in summary about those latest developments? The conference was staged under the banner, Quality, Honesty and Beauty in Science and Technology Communication, reflecting its location in a city associated with Galileo, da Vinci and Michelangelo.

Evaluation, aesthetics and ethics were in the spotlight and the first two of those attracted particular attention from participants. Much of the material on using artistic means to communicate science related closely to science-and-art discussions that have gone on elsewhere but not so intensely at PCST conferences or in journals like JCOM. In this domain and in others - for example, the very lively sector of science centres with its own professional networks and conferences - there were strong indications of the potential for valuable exchanges and collaborations between near-neighbours.

Discussion of theatrical, literary or visual representations of scientific information and ideas also raised questions of ethical judgements, as indicated in the visually stimulating plenary talk by photographer Felice Frankel. But only a small number of presentations tackled ethical issues of science communication head-on, while some more focused on communication of ethical issues in science.

From the individual papers submitted it is clear that evaluation of science communication is an increasing concern of practitioners and researchers in the field. But attention is focused mainly on efficacy and effectiveness of various methods of public engagement (as it is increasingly called) and less on participants' experiences, and much less on the quality of the various kinds of popular representations of science.

Massimiano Bucchi in his opening plenary talk and John Durant, one of the founding figures of the PCST academic community, in his contribution to a plenary panel, both situated science communication as cultural practice. Indeed, Durant suggested that a new 'cultural model' of science communication is emerging. If that is so, and if Bucchi's concern with matters of style is well placed, then PCST practitioners and researchers need to develop the capacities of artistic imagination and cultural critique.

This is certainly a different agenda from those that dominate the field. Based on the abstracts submitted to the PCST conference, it appears that the three primary areas of concern are: mass media coverage of science; experiences and attitudes of scientists in public communication; methods of public engagement. These seem in general rather familiar, though the details are changing and the geographic spaces are extending.

Rick Borchelt in a plenary talk gave a first sight of his analysis of published research in science communication and commented that this research was becoming repetitive, perhaps too reliant on methods such as surveys. That reflects what was called the "sociological turn" in science communication. It will be interesting to see what influence the suggestions at PCST2012 of a "cultural turn" have in the coming years.

Brian Trench 


\section{Author}

Brian Trench is a researcher and trainer in science communication based in Dublin, Ireland. He was cochair, with Massimiano Bucchi, of the programme committee of PCST2012. He is co-editor, also with M. Bucchi, of Handbook of Public Communication of Science and Technology (Routledge, 2008).

E-mail: brian.trench@dcu.ie.

How TO CITE: $\quad$ B. Trench, Review of PCST2012 conference: where is communication going?, Jcom 11(03) (2012) E 